Article

\title{
Precise Determination of Liquid Layer Thickness with Downward Annular Two-Phase Gas-Very Viscous Liquid Flow
}

\author{
Krystian Czernek * ${ }^{*}$ and Stanisław Witczak \\ Department of Process and Environmental Engineering, Faculty of Mechanical Engineering, Opole University of \\ Technology, ul. Prószkowska 76, 45-758 Opole, Poland; s.witczak@po.edu.pl \\ * Correspondence: k.czernek@po.edu.pl; Tel.: +48-77-449-8778
}

Received: 9 November 2020; Accepted: 7 December 2020; Published: 10 December 2020

check for updates

\begin{abstract}
The paper presents the characteristics of the original optoelectronic system for measuring the values of hydrodynamics of two-phase downward gas-very viscous liquid flow. The measurement methods and results of the research on selected values describing gas-oil two-phase flow are presented. The study was conducted in vertical pipes with diameters of 12.5, 16, 22, and $54 \mathrm{~mm}$. The research was conducted with the superficial velocities of air $j_{\mathrm{g}}=0-29.9 \mathrm{~m} / \mathrm{s}$ and oil $j_{1}=0-0.254 \mathrm{~m} / \mathrm{s}$, which corresponded to the values of gas stream density $g_{g}=(0-37.31) \mathrm{kg} /\left(\mathrm{m}^{2} \mathrm{~s}\right)$ and of liquid $g_{1}=(0.61-226.87) \mathrm{kg} /\left(\mathrm{m}^{2} \mathrm{~s}\right)$, in order to determine the influence of air and oil streams on the character of liquid films. The variations in oil viscosity were applied in the range $\eta_{1}=(0.055-1.517)$ Pas. The study results that were obtained with optical probes along with computer image analysis system revealed vast research opportunities in terms of the identification of gas-liquid two-phase downward flow structures that were generated as well as the determination of the thickness of liquid film with various level of interfacial surface area undulation. The designed and constructed proprietary measuring system is also useful for testing the liquid layer by determining the parameters of the resulting waves. It is considered that the apparatus system that is presented in the article is the most effective in examining the properties of liquid layers of oil and other liquids with low electrical conductivity and a significant degree of monochromatic light absorption. In view of noninvasive technique of measuring characteristic values of liquid films being formed, the above measuring system is believed to be very useful for industry in the diagnostics of the apparatus employing such flows.
\end{abstract}

Keywords: two-phase flow; very viscous liquid; liquid film; optoelectronic system

\section{Introduction}

The two-phase gas-very viscous liquid flow is a phenomenon occurring in a number of technological systems applied in modern industry both in relation to transport and thermal processing of liquid substances. Chemical, petrochemical, pharmaceutical, or food industries benefit from two-phase gas-liquid systems. The simultaneous presence of both phases: gas and very viscous liquid that arises from the nature of these processes, is very demanding while operating various apparatus. Exploitation problems are mainly attributable to the significant stochasticity of two-phase gas and liquid flow in variously oriented channels, Padilla et al. [1], Gabriel et al. [2], Pietrzak et al. [3], Singh et al. [4], and Colombo et al. [5].

In the flow mentioned above-depending on the flow rates of liquid and gas phases along with physical properties of mixture components-various structures of this flow are likely to occur. The maintenance of adequate process parameters along the flow poses a challenge and it is conditioned 
in the stability of flow structure, depending on channel geometry and liquid properties. Consequently, solutions providing the proper work of processing apparatus and eliminating adverse occurrences in the process assume growing importance. The occurrences mentioned above are the flow instability, sediments on the surface of the heating pipes of interchangers and vaporizers, liquid foaming, and interphase surface instability. Unfortunately, only few scientific papers are concerned with the flow of gas and very viscous liquid hydrodynamics and research on two-phase flow with concurrent heat exchange seem to be even scarcer.

Padilla et al. conducted the studies on pressure drop and flow structures in curved pipe channels with diameter of $6.7 \mathrm{~mm}$ [1], whereas Gabriel et al. undertook studies in rectangular curved channels [2]. In the studies flow patterns of gas and liquid mixture were observed. As an interesting complement to the papers mentioned above, Pietrzak et al. [3], in their studies in pipes with the internal diameters of $0.016,0.022$, and $0.03 \mathrm{~m}$, determined gas and liquid volume participation and devised maps of this type of two-phase flow.

A much larger proportion of papers relate to the studies that involve quantities characterizing two-phase flow in the conditions of horizontal flow. The structures were observed by, among others, Singh et al. [4] while studying phase volume fractions during the flow of liquid nitrogen flow through horizontal channels. Research concerned with the area of identification of flow structures and the determination of volume ratio of the phases was also carried out for such a system by Colombo et al. [5] while using water and mineral oil and a trap method applied in plexiglas channels. In the study that was reported by Charnay et al. [6], the results of qualitative visual observation of two-phase flow structures are explored with regard to various refrigerants accompanying flow in horizontal channels. The classification of areas that correspond to the occurrence of different forms of two-phase flow in the form of so-called flow maps. Yang et al. [7] presented conducted several types of experiments while using similar refrigerants in addition to the analysis of the heat transfer process during. The study by Rassame and Hibiki presents the results of research that was concerned with the determination of two-phase flow structures in horizontal channels, combined with the calculations with regard to the volume ratios of individual phases [8]. This study also conducted a review of the calculation models that are based on drift-flux correlation to calculate the gas volume fraction. Whan $\mathrm{Na}$ and Chung carried out the measurements related to the determination of the heat transfer coefficient during flow in horizontal micro-channels [9]. On the basis of this study, models were developed that can be applied for the calculation of liquid film thickness, pressure drops, and heat transfer coefficient at the interface. In rectangular mini-channels, research involving the determination of the heat transfer coefficient was conducted by Jige and Inoue [10], while using refrigerant flow. The modeling of the liquid film thickness during horizontal flow in terms of the intensification of momentum and heat exchange formed the subject area of the research conducted by Cioncolini and Thome [11]. The database used in modeling included nine fluids (water, two hydrocarbons, and six refrigerants) for vertical and horizontal pipes with the diameter range of 1.03-14.4 mm and pressures between 0.1 and 7.2 MPa.

Vertical flow channels dominate in both academic research and full-scale plants. Interphase surface is the most significant value determining heat and mass exchange conditions. The surface value mainly depends on flow structures that originate as a result of mutual relations between flow parameters and physicochemical properties of gas and liquid. Ebrahimi-Mamaghani et al. [12], Hamidi et al. [13], Liu et al. [14], Smith et al. [15], and Shen et al. [16] conducted studies to identify the above in conditions of heat exchange. Additionally, the testing involved gas and liquid volume participation. Shen et al. also conducted the studies on the volume participation and factors velocity during the ascending flow in rectangular channels [17] in order to verify previous tests by Shen et al. [18] concerning pressure loss during the flow. Liquid layer thickness directly determining interphase surface value was then tested by Ju et al. [19] and Liu et al. [20], who also conducted numerical simulation. Comprehensive experimental studies on that flow were also within the interest of Dang et al. [21], who applied pipes with a diameter of $25.4 \mathrm{~mm}$. By the use of conductivity probe, they tested the types of flow patterns, 
velocity, and Sauter mean diameter of gas bubbles velocity, its volume participation, and the interphase surface of interacting factors.

Descending flow is another type of two-phase flow of gas and liquid that is recommended in vaporizers and pipe reactors. Gao et al. [22] and Lee et al. [23] verified the influence of the structures of this type of flow on heat transfer coefficient. Jiang et al. [24] investigated the relations between flow patterns and pressure loss value. The studies on flow patterns and determining the areas of their occurrence were also the subject of research conducted by Julia et al. $[25,26]$. The maps of flow were formulated as a result of their studies. The influence of two-phase flow patterns on the value of the heat transfer coefficient was tested by Lee et al. [23]. Qiao et al. [27] and Xue et al. [28] also formulated the maps of two-phase flow in circular section channels.

In the studies of two-phase flow, a number of theoretical and numerical models have been widely applied. They apply the modelling of multiphase flow dynamics control for a variety of flow patterns and value change of flow pressure drop and volume participation of phases. In this group of studies, the discoveries of Dell'Acqua et al. [29], Afshari et al. [30], and Leporini et al. [31] are worth mentioning as a significantly valuable source of complementary knowledge in this area.

For detailed analysis of numerical models, it is advisable to study selected parameters whose values can only be obtained through experimenting with over determined flow regimes. The flow widely used in the industry is annular flow of gas and liquid of various properties.

The annular flow is frequently defined as thin-layer flow of liquid with free surface formed as a result of gravity, shear stress, and other external influences. In comparison to other representative measurements, the above flow is typically of small thickness, which significantly influences its characteristics and areas of its formation. Waves of various length and amplitude occurring on the gravitational flow free surface and on the gas-liquid forced flow interfacial surface significantly impede any thorough theoretical description of the flow phenomena. In terms of liquid film hydrodynamics, the values of the mean thickness for various surface state and the values determining changes of the interfacial surface state appear to be very interesting.

The state of liquid film surface and its local thickness are frequently assessed based on flowing mixture being visually observed. For the case when observation is not feasible, various vision systems or nonconventional observing techniques are applied, including:

- $\quad$ special phototechnical system Al-Kizwini et al. [32], An et al. [33], Da Silva et al. [34] Damsohn and Prasser [35], Hanafizadeh et al. [36], Marchetti and Svendsen [37], Tibiriçá et al. [38],

- $X, \gamma$ or $\beta$-ray photography Boden et al. [39], Heindel et al. [40], Osta et al. [41], Roshani et al. [42], and Roshani et al. [43,44],

- optoelectronic detection of structure transverse image Charalampous et al. [45], Jand apper-Jaafar et al. [46],

- CT scan Ismail et al. [47], Li and Soleimani [48], Tschentscher et al. [49], and Zhang et al. [50],

- thermographic systems Akafuah et al. [51],

- sonic and ultrasonic systems Albion et al. [52], Chiou and Li [53], Fang et al. [54], Furlan et al. [55], Wang et al. [56], and Xu et al. [57],

- electronic and electromagnetic systems Hazuku et al. [58], Hu et al. [59], and Liu et al. [60], and

- holographic photography de Jong et al. [61].

Despite such a diversity of techniques, a single system that is capable of measuring the above values with two-phase dielectric very viscous liquid flow has not been constructed so far.

The goal of this paper is to indicate the metrological potential of the proprietary optoelectronic system that is used to measure the hydrodynamic values of descending annular two-phase flow of gas and viscous liquid in vertical pipes. The paper presents the characteristics of original optoelectronic system, selected tests and analysis results concerning the identification and description of flow patterns that formed as well as liquid layer thickness determining the interphase surface condition. 
New dependencies that are used to calculate mean values of liquid film thickness and interphase surface values are also introduced.

\section{Materials and Methods}

\section{Experimental Setup}

An experimental stand was built in order to study the hydrodynamics of the fluid film and to learn about the phenomena accompanying its flow (Figure 1).

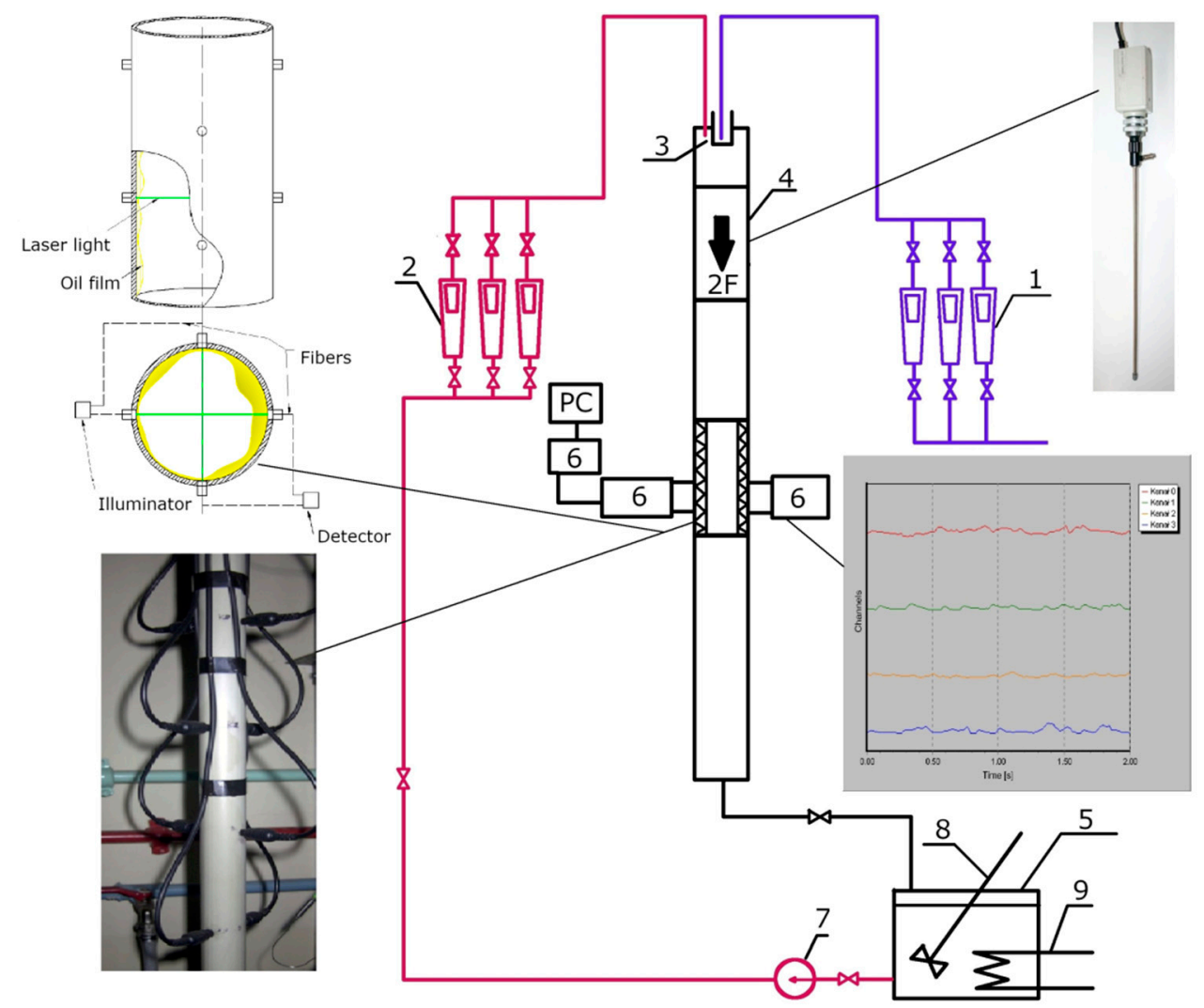

Figure 1. Test stand diagram: 1-rotameter of air, 2-rotameter of oil, 3-feeding chamber (central jet), 4-measuring channel, 5-oil tank, 6-system of optoelectronic sensor, 7-pump, 8-mixer, 9-heater.

When considering the need to describe the hydrodynamics of gas-liquid two-phase flow for viscosity over 0.1 Pas, the studies on influence of liquid viscosity on the type of liquid films being formed and their average thickness were conducted.

The working factors that were used in the study were oils and air of different quality. Their fluxes were measured in two independent circuits while using Kobold and Rotametr flow meters. The accuracy of the flow meters ranged from 1.4 to $4.5 \%$.

With that end in view, an optoelectronic measuring system that consists of optical probes, software, and optical endoscope was completed. While measuring the oil layer thickness, optical signal rejection was measured with a photo detector that was illuminated by a diode illuminator located opposite. Optoelectronic sensors were joined to a personal computer that was equipped with a TAURON digital measuring system for image registration and acquisition and MVSD8 card along with dedicated software. The sensors were applied in order to measure the flowing liquid local thickness and determine its undulation. Figure 2 shows the measurement schematic diagram along with the above installation part. 

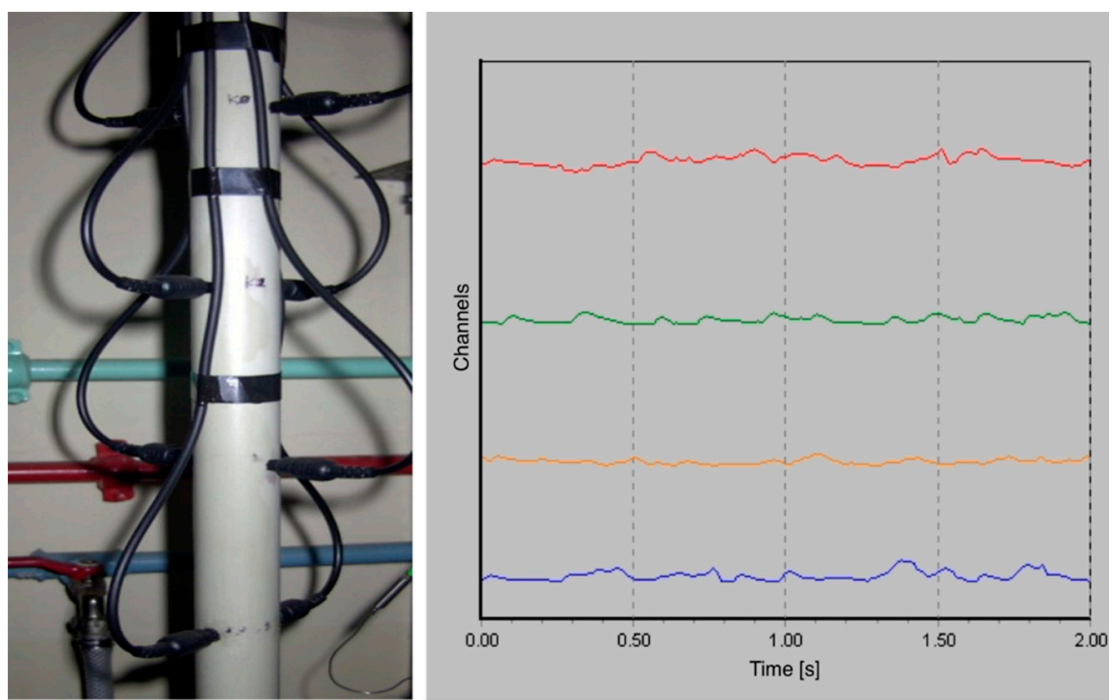

Figure 2. Light absorption measuring system.

The length of light wave that was emitted by the illuminators was experimentally selected after the spectrum of oil sample absorption had been measured (Figure 3) and it was of $470 \mathrm{~nm}$ (blue color), owing to the most significant signal rejection of oil in that spectrum range was observed.

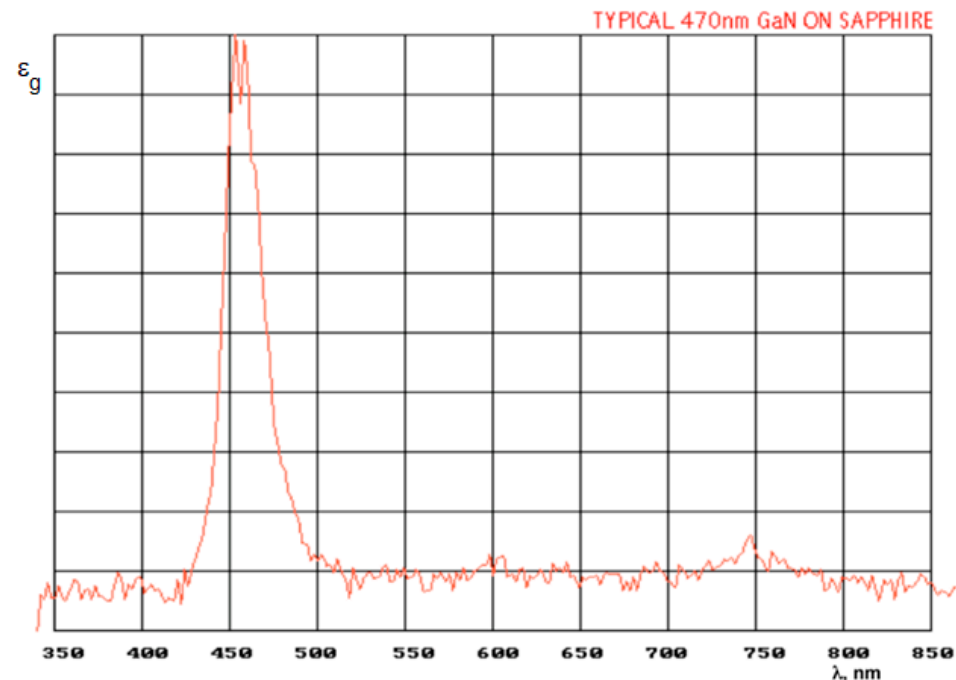

Figure 3. Light absorption spectrum for ITERM-12 oil.

The light source from illuminators and return signal to the photo detectors were connected to the measuring controller by optical wave-guides, two for each measuring probe. The measuring probes were placed in $100 \mathrm{~mm}$ intervals and pairs of probes $\mathrm{K} 0-\mathrm{K} 2$ and $\mathrm{K} 1-\mathrm{K} 3$ were located perpendicularly to each other. Figure 4 presents the diagram of measuring light absorption. 


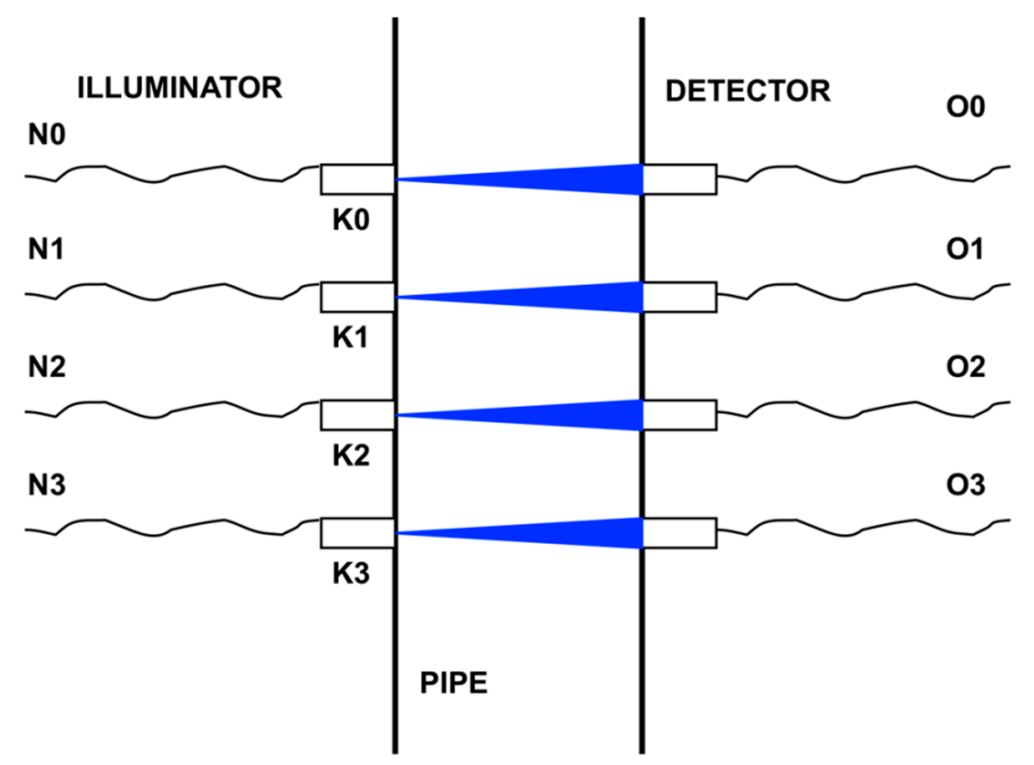

Figure 4. The rule of measuring light absorption.

The measuring driver was equipped with signal amplifiers from photo detectors and LED illuminators diodes drivers. The driver was controlled by a AT89S52 microprocessor with software enabling the communication with the measurement controlling program in a personal computer.

The system was factory-calibrated and ready to work; however, while the tank was filled with oil, the system required re-calibration with a calibrator that was constructed for that specific purpose (Figure 5).
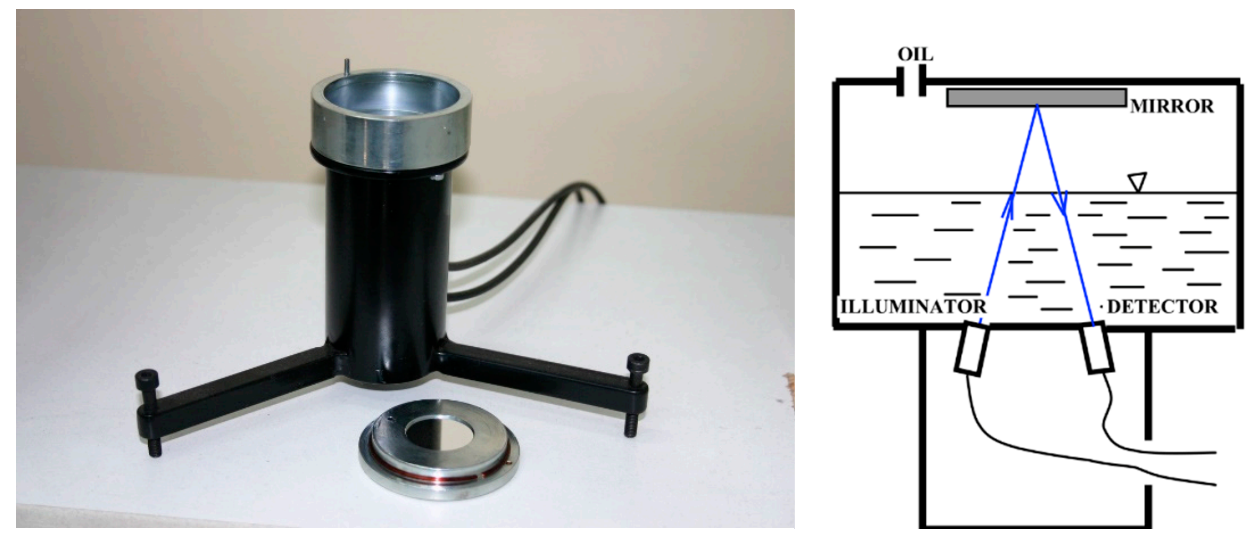

Figure 5. The calibrator image and work diagram.

The elaborated software could be applied in order to calculate the wave period, frequency, and velocity. After measurements, the program calculated the average total thickness of the oil film on the pipe walls. The character of the waves of flowing oil films was determined in two stages. At first, a high-resolution digital camera using the SVHS system was located in the transparent part of the measuring channel. The camera registered the occurrence of flow patterns being analyzed afterwards in the measuring system and other programs for image analysis, which provided the means to determine the characteristics of the liquid film waves. The obtained results were verified at the next stage. The digital camera was equipped with a CCD-video interface, so it was possible to couple it with a stiff endoscope. (Figure 6). 


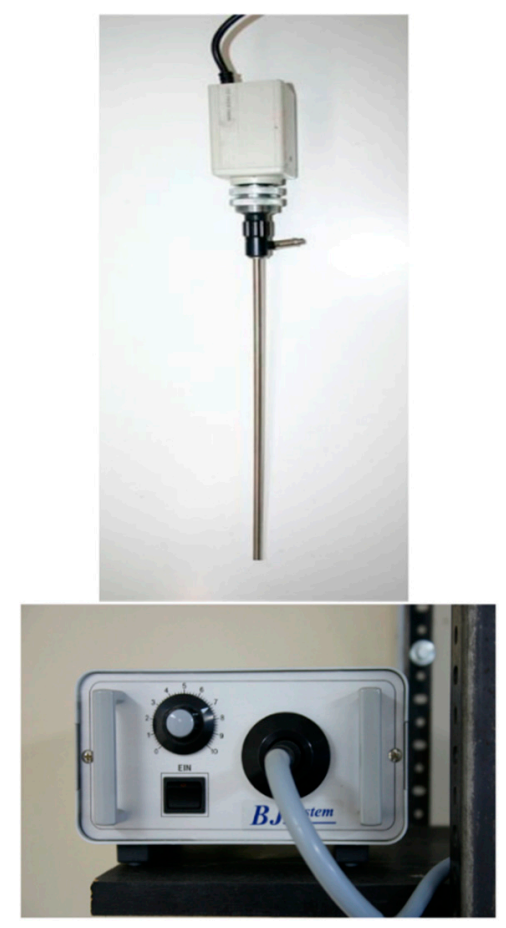

Figure 6. Stiff endoscope.

The optical endoscope system and computer software for image recording and analysis offered the assessment of the nature of the liquid film flow in the channel cross-section. The combination of the results from the endoscope and optical probes allowed for extensive experimental research to identify different types of annular flow and their areas of occurrence. Selected quantities that were characteristic for the flows of high-viscosity dielectric liquid films were also determined.

The obtained images of the liquid film flow in the cross section allowed for observing a level and character of the interface undulation for different flow parameters of gas and very viscous liquid.

\section{Results and Discussion}

The gravitational flow of a film and its flow with a gas were both investigated in order to determine the influence of velocity of both phases and liquid viscosity on the liquid film formation. The study was performed in vertical pipes of $12.5,16,22$, and $54 \mathrm{~mm}$ in diameter. In order to determine the influence of air and oil streams on the character of the forming liquid films, the investigation was conducted for superficial velocities of air $j_{\mathrm{g}}=0-29.9 \mathrm{~m} / \mathrm{s}$ and oil $j_{1}=0-0.254 \mathrm{~m} / \mathrm{s}$, which corresponded to densities of gas stream $g_{\mathrm{g}}=0-37.31 \mathrm{~kg} /\left(\mathrm{m}^{2} \mathrm{~s}\right)$ and liquid stream $g_{1}=0.61-226.87 \mathrm{~kg} /\left(\mathrm{m}^{2} \mathrm{~s}\right)$. The oil viscosity was being changed within $\eta_{1}=0.055-1.517$ Pas.

\subsection{Flow Patterns}

Figure 7 presents the flow patterns that were obtained from the study. Several groups of flow patterns were distinguished, depending on liquid hold-up with the increasing gas phase stream. If a liquid stream that was delivered to the pipe was sufficient to the total hold-up of the channel, bubble flow, plug flow, stalactite flow, and foam flow, being a transient flow leading to annular flow were observed. 


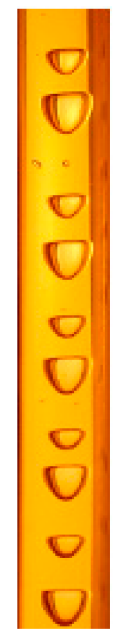

B

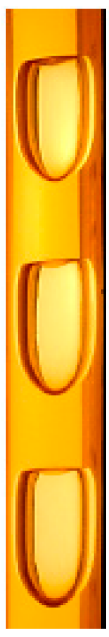

P

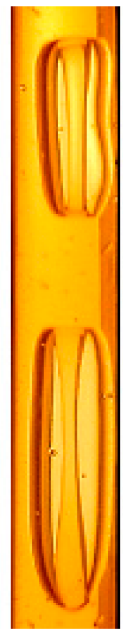

$S$

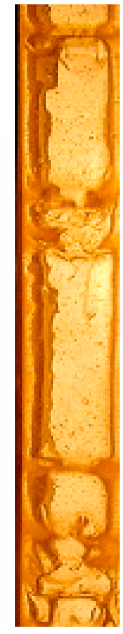

$\mathbf{F}$

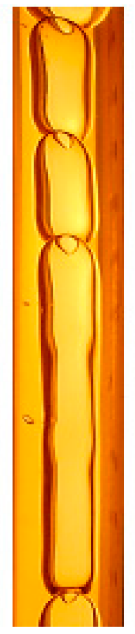

AR

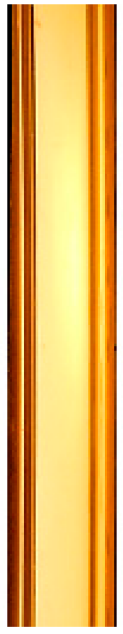

AL

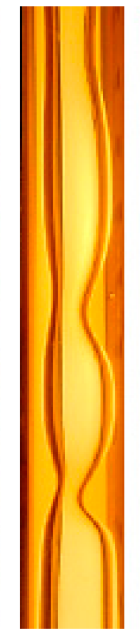

AW

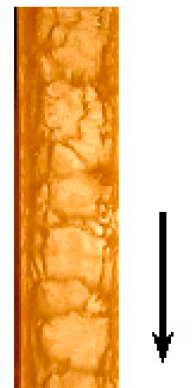

$\mathrm{AH}$

Figure 7. Patterns of downward two-phase gas-very viscous liquid flow in vertical pipes: B-bubble, $\mathrm{P}$-plug, S-stalactite, F-foam, AR-annular core, AL-annular smooth, AW-annular wave, AH-annular hydraulic.

In bubble flow, the gas phase, which is in the shape of regular gas bubbles with linear dimensions significantly lower than the pipe diameter, is diffused in the continuous liquid phase. The bubbles invariably assume the form of revolving paraboloid segments and individually relocate along the pipe axis. In plug flow, the gas phase takes the form of large paraboloid bubbles (plugs) with a length comparable to the channel diameter flowing in continuous liquid phase. Within the rear plug wall, a significant deformation of interfacial surface is observed in the form of central convex with the inward-looking top. The plugs flow individually along the pipe axis. In stalactite flow, the gas phase, which is in the shape of large toroidal bubbles and the length comparable to the channel diameter or significantly longer, occurs in a continuous liquid phase. The part of the liquid in the shape of thin spout relocates within the gas torus. In foam flow, none of the phases occurs in continuous form. The interfacial surface experiences significant changes in terms of size and shape and no privileged structures were distinguished. The intensive mixing of phases along the pipe axis and radius accompanies the flow.

Various forms of annular flow were obtained with lower liquid streams and the increase of the gas supply. In annular core flow, both phases occur in a continuous form. Gas in the shape of a thin core relocates along the pipe axis. Smooth or minimally wavy liquid film flows with high velocity and its thickness is compared to a gas core diameter. In annular smooth flow, both phases occur in continuous form. A smooth liquid film thoroughly covering the pipe perimeter flows with low velocity. Gas relocates along the pipe axis implicating no waves. In annular wave flow, both phases occur in continuous form. Liquid flows along the wall of the wavy film and gas relocates along the pipe axis. The increase of gas velocity changes the shape and amplitude of waves. In annular hydraulic flow, both phases occur in continuous form. Gas concentrates in the shape of continuous core along the pipe axis. Thin liquid layer flow humidifies the pipe perimeter. The undulation of interfacial surface is intensive. With very high gas velocities, the part of the liquid in the shape of small drops relocates with gas.

The possibilities of various annular flow occurrence were analyzed. Figure 8 presents various states of annular flow observed and registered in measurements. 

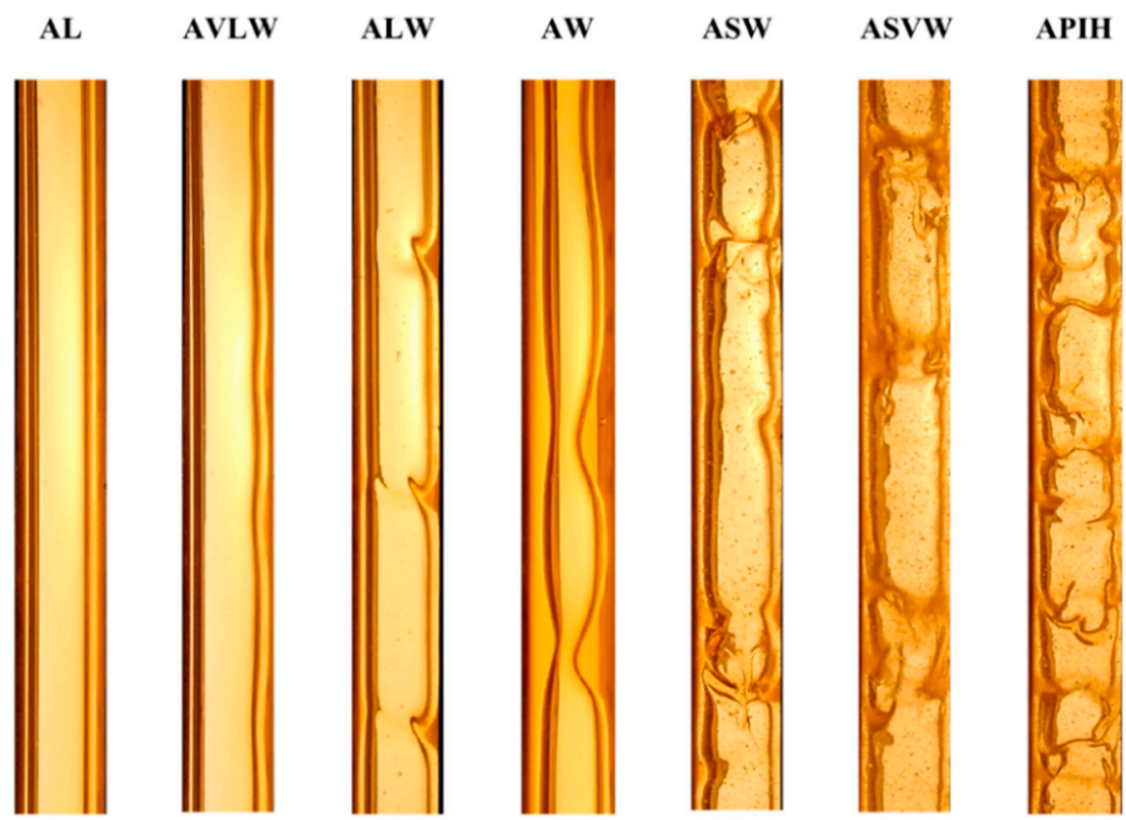

AH

Figure 8. Flow patterns accompanying co-current downward gas-very viscous liquid flow: AL—smooth film, AVLW—film with very light waves, ALW—film with light waves, AW—wavy film, ASW—very wavy film, AVSW—very wavy film, APIH—transient hydraulic flow, AH—hydraulic film.

The images that were obtained from an optical endoscope (Figure 9) reveal the diverse character of the flowing liquid films. In the case of low liquid velocities with a relatively large range of gas velocities, a smooth film is usually formed. The size and character of the waves being formed with various amplitudes and frequency were mainly dependent on liquid stream and viscosity and the gas phase velocity.

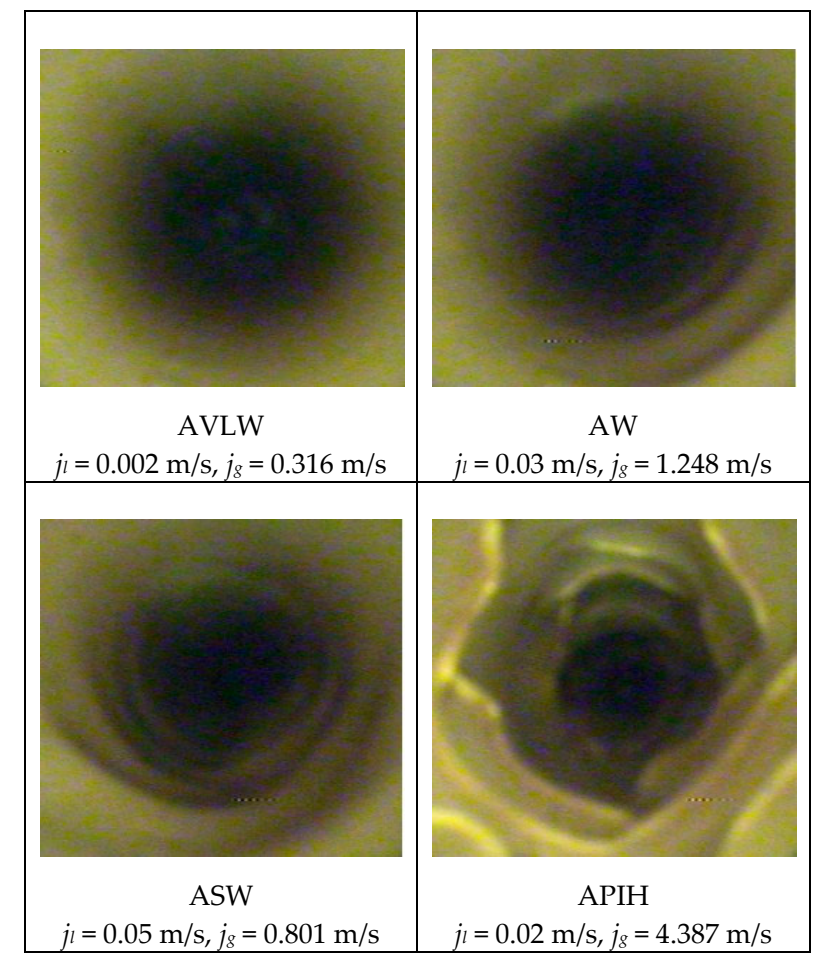

Figure 9. Influence of flow parameter on oil film undulation level with viscosity of 0.335 Pas in a pipe with diameter of $0.054 \mathrm{~m}$. 
Throughout an extensive stage of experimental studies, sinusoidal waves, rolling waves, and irregular capillary waves, with lengths that depend on the gas phase velocity changes, were observed. Both long (0.1-0.5) $\mathrm{m}$ and short (0.001-0.01) $\mathrm{m}$ waves were observed. In strongly waving flows and annular hydraulic flows, liquid film surfaces were mostly irregular and complex undulation states as a result of interference of different wave types were observed.

The authors of the paper compared the obtained results of the research in the area of descending annular flow structures occurrence with the flow maps that are available in the foregoing literature Oschinowo et al. [62], Troniewski et al. [63], Yamazaki et al. [64], and Crawford et al. [65].

In view of conducting tests in an unprecedented range of liquid viscosity changes, satisfying compatibility was not obtained. Consequently, a propriety and universal map of flow was formulated and it is shown in Figure 10.

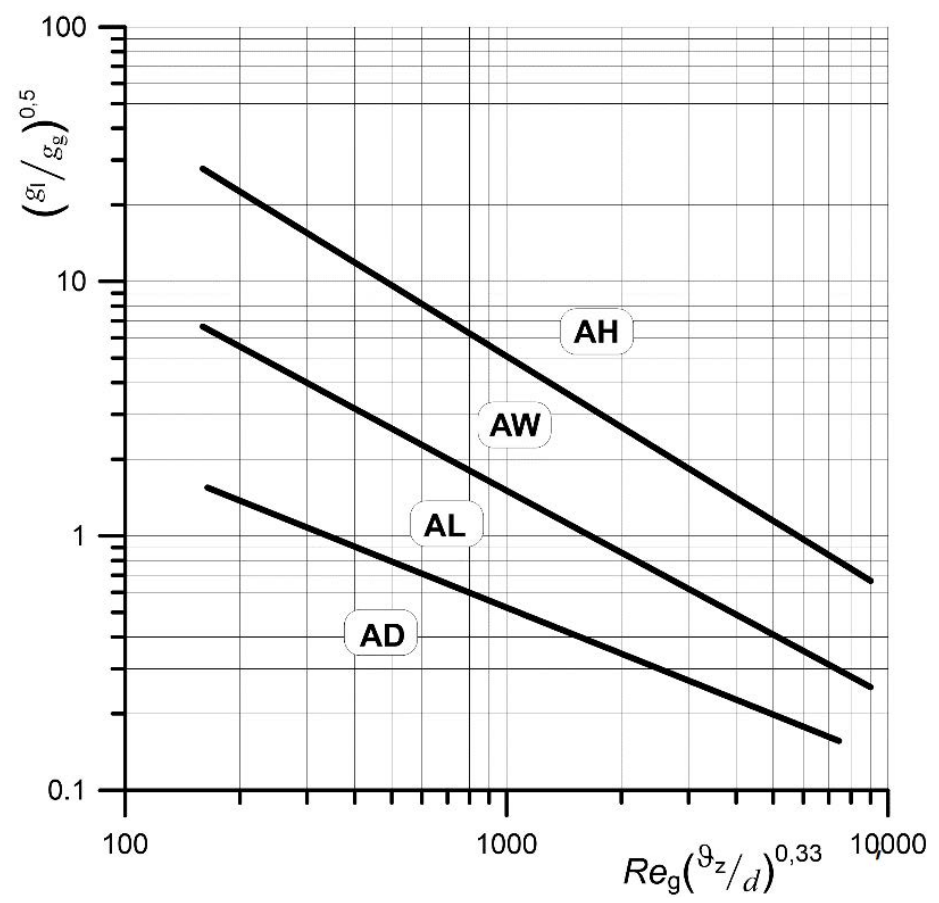

Figure 10. Universal map of annular descending two-phase flow of gas and very viscous liquid in vertical pipes.

Based on obtained test results, the correlational dependencies describing individual limits of forming annular types of flow were determined i.e.,

(a) the limit AD-AL between full wettability of inner pipe wall and laminar flat film.

$$
\left(\frac{g_{1}}{g_{\mathrm{g}}}\right)^{0.5}=404\left[\operatorname{Re}_{\mathrm{g}}\left(\frac{\vartheta_{\mathrm{z}}}{d}\right)^{0.33}\right]^{-0.809},
$$

(b) the limit AL-AW between flat and wavy annular flow

$$
\left(\frac{g_{1}}{g_{\mathrm{g}}}\right)^{0.5}=33\left[\operatorname{Re}\left(\frac{\vartheta_{\mathrm{z}}}{d}\right)^{0.33}\right]^{-0.601}
$$

(c) the limit AW-AH separating wavy and hydraulically developed forms

$$
\left(\frac{g_{1}}{g_{\mathrm{g}}}\right)^{0.5}=3035\left[\operatorname{Re}\left(\frac{\vartheta_{\mathrm{z}}}{d}\right)^{0.33}\right]^{-0.925},
$$


Calculations included statistical tests that were conducted by the adoption of literature recommendations and they showed that the formulated dependencies were correct with a probability of 0.95 at the average correlation rate value of 0.986 .

\subsection{Liquid Film Characteristics}

The thickness of the forming liquid films and efficient value of surface at the liquid-gas boundary seemed to be interesting in terms of liquid film hydrodynamics. The measurements of the liquid film thickness were performed with an optoelectronic system enabling the determination of real-time variations in the liquid film thickness (Figure 11).
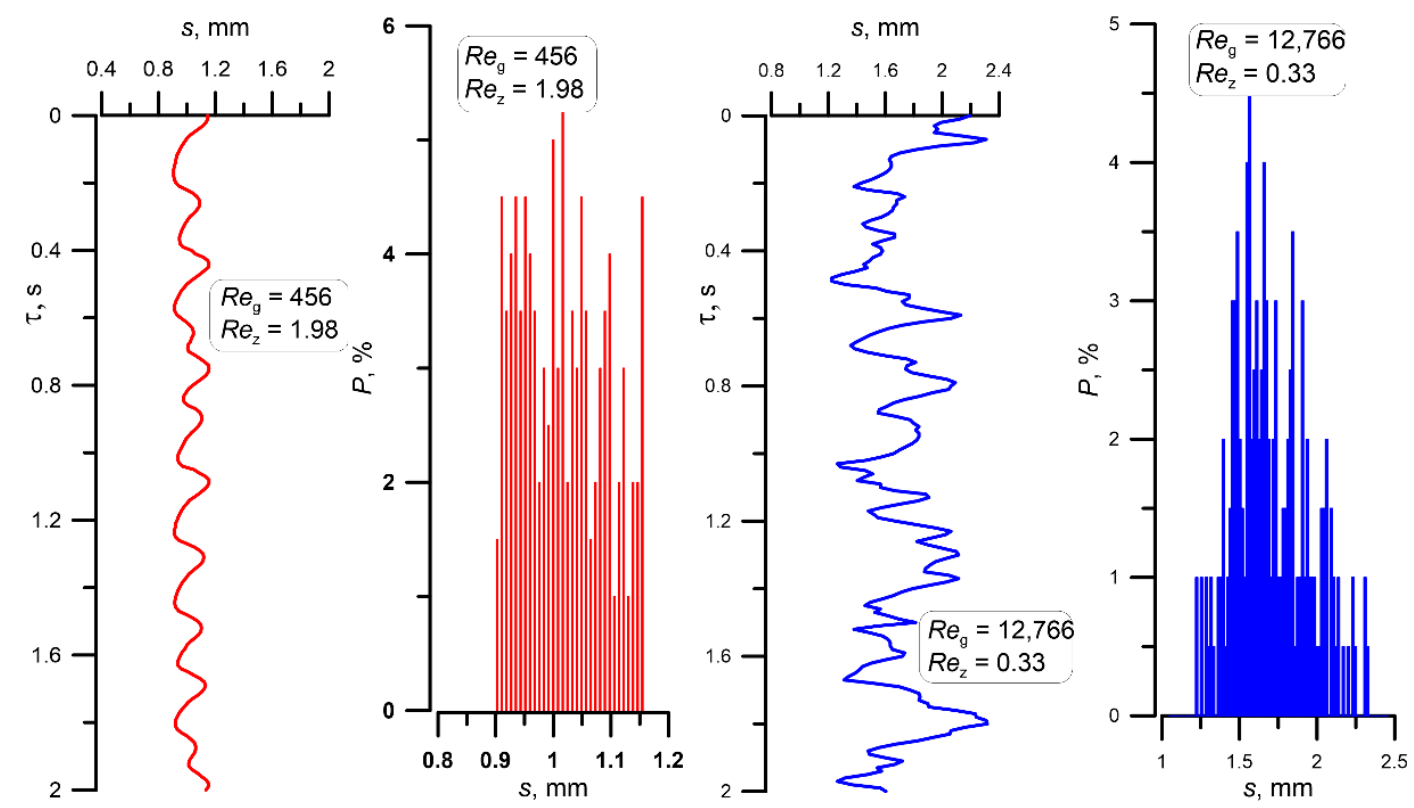

Figure 11. Exemplary study results of surface state and thickness distribution of the liquid film.

The average of the measured film thickness was assumed as the integral mean.

The obtained data reveal that all of the parameters strongly influence the liquid film thickness within the total range of processing data. The increase of liquid viscosity invariably implicates the increase of liquid layer thickness, whereas the increase of gas phase velocity, at a constant liquid velocity, implicates the decrease of film thickness. Figures 12 and 13 present the relation.

This tendency was observed for all pipe diameters and liquid viscosities. It is to be noted that the above tendency is particularly distinct for the turbulent flow of the gas phase. For the low velocities of the gas phase, the liquid film thickness is close to the values that were obtained for gravitational flow of the liquid.

The following relationship has been proposed in order to describe the influence of the gas stream phase on the liquid film thickness $s$ in relation to conditions attending the gravitational flow $s_{0}$ :

$$
\frac{s}{s_{0}}=\frac{1}{1+5.68 \cdot 10^{-3} R e_{\mathrm{z}}^{0.132} R e_{\mathrm{g}}^{0.471}}
$$

with the liquid film thickness $s_{0}$ should be calculated from the equation:

$$
\begin{aligned}
& \frac{s_{0}}{\vartheta_{\mathrm{z}}}=0.8252 R e_{\mathrm{z}}^{0.516}, \text { dla } R e_{\mathrm{z}}<2 \\
& \frac{s_{0}}{\vartheta_{\mathrm{z}}}=0.9335 R e_{\mathrm{z}}^{0.334} \text {, dla } R e_{\mathrm{z}}>2
\end{aligned}
$$


where $\vartheta_{\mathrm{z}}=\left(\frac{\eta_{l}^{2}}{\check{g} \rho_{l}^{2}}\right)^{1 / 3}, R e_{\mathrm{z}}=\frac{4 \Gamma}{\eta_{l}}, \Gamma=\frac{\dot{m}_{l}}{\pi d}, R e_{\mathrm{g}}=\frac{j_{\mathrm{g}} d \rho_{g}}{\eta_{g}}$, and $\breve{g}$-gravitational acceleration, $\dot{m}_{l}$-mass flow.

Equation (4) was developed with the correlation coefficient of 0.984 and the mean value of standard deviation 0.181 .

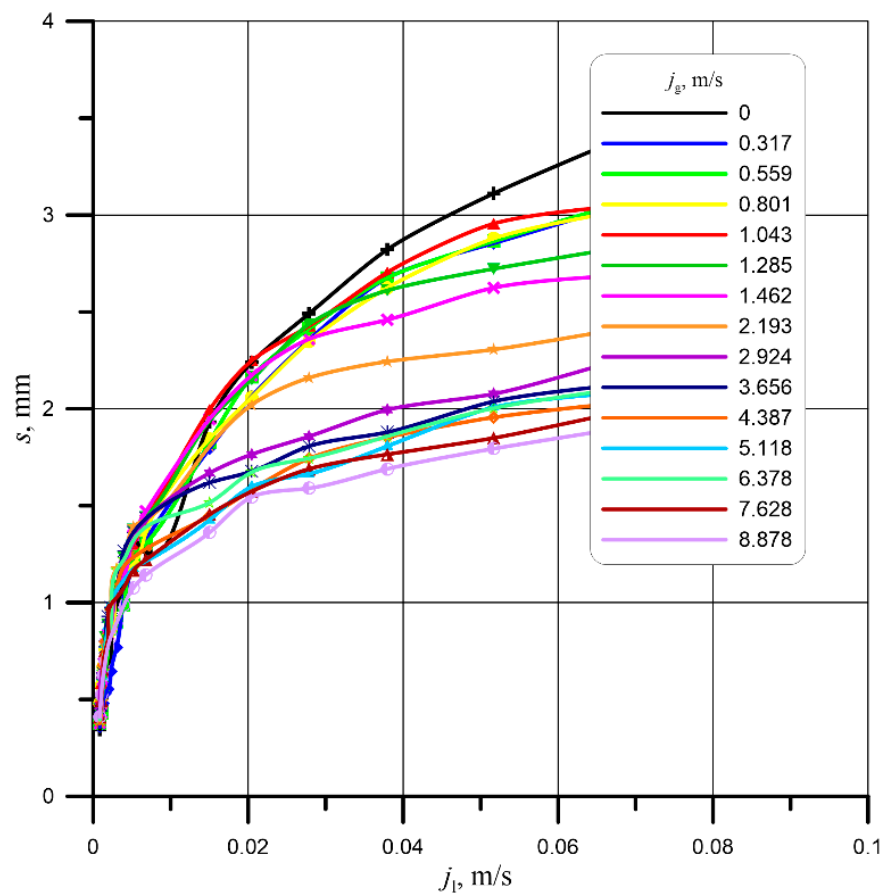

Figure 12. The liquid film thickness in downward two-phase air and oil viscosity $\eta_{1}=0.371$ Pas in pipe $d=0.022 \mathrm{~m}$.

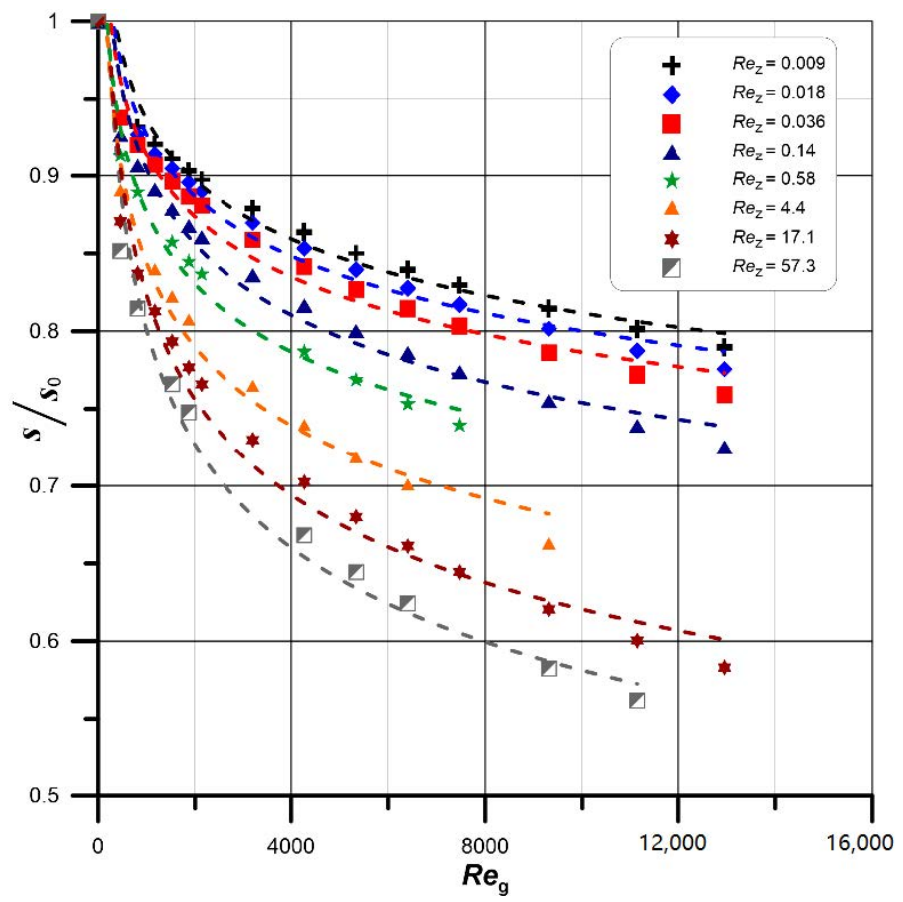

Figure 13. Influence of the gas stream on changes of the liquid film thickness in relation to the thickness occurring in gravitational flow.

Because the interfacial surface value forms an important quantity that affects conditions of heat and mass transfer, an attempt was made to determine it. To that end, changes of the liquid film 
thickness versus time were used to calculate the contact surface of gas and liquid $F_{2 \mathrm{~F}}$. In order to determine $F_{2 \mathrm{~F}}$ related to the internal surface of the pipe $F_{\mathrm{p}}$, it was assumed that:

$$
F_{\mathrm{p}}=\pi d \Delta L_{\mathrm{cal}}
$$

where:

$$
\Delta L_{\mathrm{cal}}=w \Delta \tau
$$

The calculated length $\Delta L_{\text {cal }}$ determines a liquid film path that is traveled at the speed of $j$, determined for the average layer thickness $s$. Figure 14 shows the obtained results.

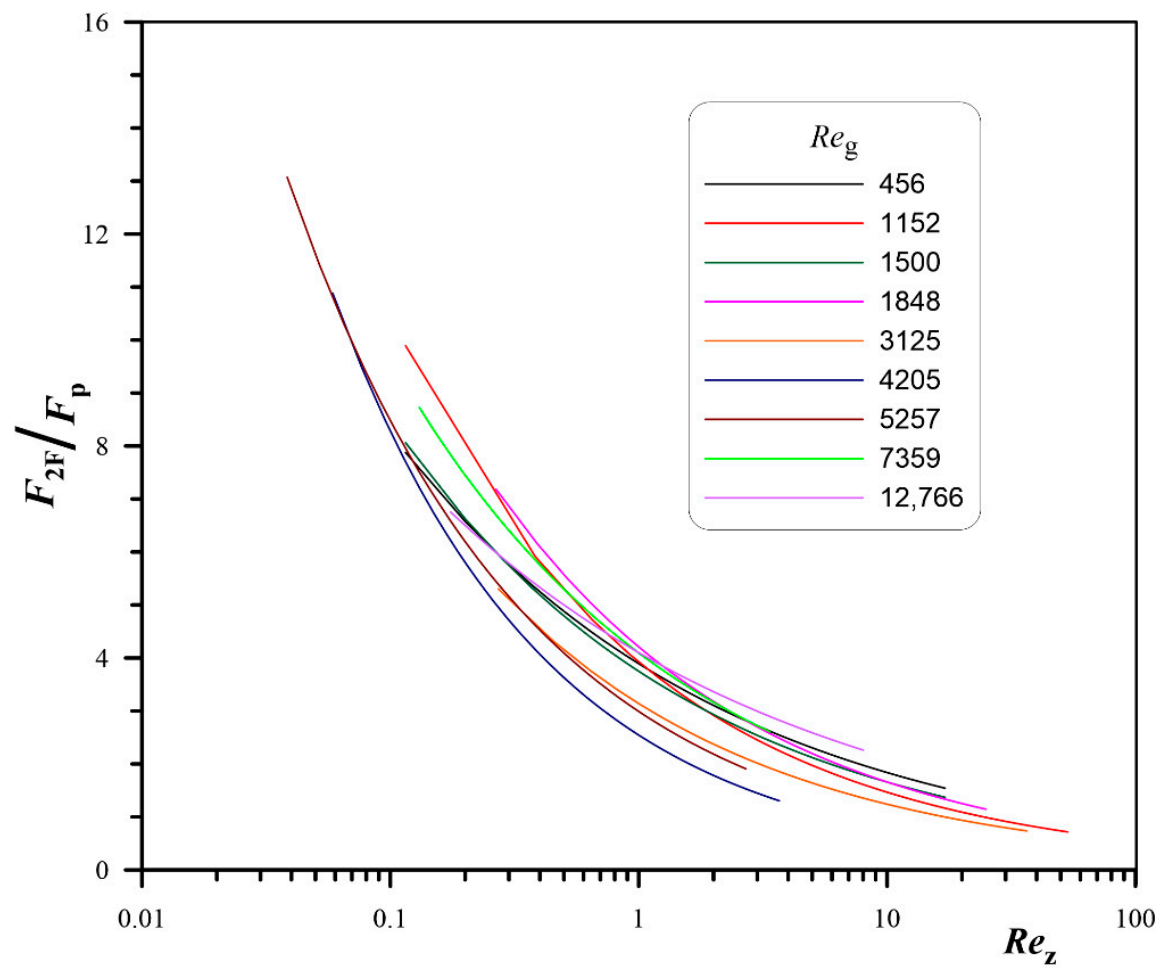

Figure 14. Influence of flow parameters on the relative value of the interface surface.

The above figure reveals that, for each $R e_{\mathrm{g}}=$ const, the increase of the Reynolds number for the liquid $R e_{\mathrm{z}}$ a significant reduction of the efficient surface is observed. It results from the increase of the liquid film thickness as well as from changes in waves nature. Expression $F_{2 \mathrm{~F}} / F_{\mathrm{p}}<1$ is significance for annular smooth flow-AL. Surface $F_{2 \mathrm{~F}}$, as a result of thickness of film liquid increase, is invariably lesser than inner surface of pipe $F_{\mathrm{p}}$. The remaining values of relations $F_{2 \mathrm{~F}} / F_{\mathrm{p}}>1$ result from various interfacial surface undulation levels.

The following equation was obtained from the theoretical considerations and correlation being calculated:

$$
\frac{F_{2 \mathrm{~F}}}{F_{\mathrm{p}}}=46.73\left(\frac{\varepsilon}{1-\varepsilon}\right)^{0.635} R e_{\mathrm{g}}^{-0.679} R e_{\mathrm{z}}^{-0.108}
$$

where $\varepsilon=\frac{j_{\mathrm{g}}}{j_{\mathrm{g}}+j_{1}}$.

The equation was developed with the correlation coefficient of 0.989 and mean value of standard deviation 0.143 .

In the consideration of the adequate precision of the above correlations (4) and (9), along with the wide range of included parameters, they could be recommended for the process calculations of apparatus with a hydraulic liquid film. 


\section{Conclusions}

The study results that were obtained with optical probes and computer image analysis system revealed vast research opportunities in terms of the identification of gas-liquid two-phase downward flow structures being formed as well as the determination of the thickness of liquid film with various levels of interfacial surface undulation.

- The study result analysis demonstrated that the application of the optoelectronic measuring system enables a range of singularities in the flowing liquid films that resulted from the oil liquid viscosity changes, to be determined. This parameter considerably affects the local and mean thickness of the flowing liquid films and its capability for reducing liquid films undulation have been observed. The increase of liquid viscosity invariably implicates the increase the liquid layer thickness, whereas the increase of the gas phase velocity at the constant liquid velocity implicates the reduction of the film thickness. This tendency has been observed for all of the investigated pipe diameters and liquid viscosities.

- The designed and constructed original measuring system is also useful for the liquid undulation level study by determining the velocity, length, and amplitude of waves being formed.

- In the apparatus system introduced in the paper, is believed to be the most effective in terms of investigating the characteristics of oil liquid films and other dielectric liquids with a significant level of absorbing monochromatic radiation.

- Dependencies allowing for calculations of values that are typical of two-phase flow dynamics, devised in the range of viscosity (55-1517) mPas unprecedented until now. Because of the above, they are highly recommended for the purposes of design and structure calculations of thin-layer reactors.

In view of noninvasive technique of measuring characteristic values of liquid films being formed, the measuring system that is introduced in the paper is believed to be very useful for industry to diagnose the working of apparatus employing such flows.

Author Contributions: Conceptualization, K.C., S.W.; Formal analysis, K.C., S.W.; Investigation, K.C., S.W.; Methodology, K.C., S.W.; Writing-original draft, K.C., S.W. All authors have read and agreed to the published version of the manuscript.

Funding: The scientific results presented in this article were obtained within the research project funded by the Ministry of Science and Higher Education of Poland.

Conflicts of Interest: The authors declare no conflict of interest.

\section{References}

1. Padilla, M.; Revellin, R.; Wallet, J.; Bonjour, J. Flow regime visualization and pressure drops of HFO-1234yf, R-134a and R-410A during downward two-phase flow in vertical return bends. Int. J. Heat Fluid Flow 2013, 40, 116-134. [CrossRef]

2. Gabriel, S.; Schulenberg, T.; Albrecht, G.; Heiler, W.; Miassoedov, A.; Kaiser, F.; Wetzel, T. Optical void measurement method for stratified wavy two phase flows. Exp. Therm. Fluid Sci. 2018, 97, 341-350. [CrossRef]

3. Pietrzak, M.; Witczak, S. Flow patterns and void fractions of phases during gas-liquid two-phase and gas-liquid-liquid three-phase flow in U-bends. Int. J. Heat Fluid Flow 2013, 44, 700-710. [CrossRef]

4. Singh, G.K.; Pradhan, S.; Tanna, V. Experimental studies of two phase flow characteristics and void fraction predictions in steady state horizontal two-phase nitrogen flow. Cryogenics 2019, 100, 77-84. [CrossRef]

5. Colombo, L.P.M.; Guilizzoni, M.; Sotgia, G.M.; Marzorati, D. Influence of sudden contractions on in situ volume fractions for oil-water flows in horizontal pipes. Int. J. Heat Fluid Flow 2015, 53, 91-97. [CrossRef]

6. Charnay, R.; Bonjour, J.; Revellin, R. Experimental investigation of R-245fa flow boiling in minichannels at high saturation temperatures: Flow patterns and flow pattern maps. Int. J. Heat Fluid Flow 2014, 46, 1-16. [CrossRef] 
7. Yang, P.; Zhang, Y.; Wang, X.; Liu, Y. wen Heat transfer measurement and flow regime visualization of two-phase pulsating flow in an evaporator. Int. J. Heat Mass Transf. 2018, 127, 1014-1024. [CrossRef]

8. Rassame, S.; Hibiki, T. Drift-flux correlation for gas-liquid two-phase flow in a horizontal pipe. Int. J. Heat Fluid Flow 2018, 69, 33-42. [CrossRef]

9. Whan Na, Y.; Chung, J.N. Two-phase annular flow and evaporative heat transfer in a microchannel. Int. J. Heat Fluid Flow 2011, 32, 440-450. [CrossRef]

10. Jige, D.; Inoue, N. Boiling heat transfer, pressure drop, and flow pattern in a horizontal square minichannel. Int. J. Heat Fluid Flow 2019, 78, 108433. [CrossRef]

11. Cioncolini, A.; Thome, J.R. Algebraic turbulence modeling in adiabatic and evaporating annular two-phase flow. Int. J. Heat Fluid Flow 2011, 32, 805-817. [CrossRef]

12. Ebrahimi-Mamaghani, A.; Sotudeh-Gharebagh, R.; Zarghami, R.; Mostoufi, N. Dynamics of two-phase flow in vertical pipes. J. Fluids Struct. 2019, 87, 150-173. [CrossRef]

13. Hamidi, M.J.; Karimi, H.; Boostani, M. Flow patterns and heat transfer of oil-water two-phase upward flow in vertical pipe. Int. J. Therm. Sci. 2018, 127, 173-180. [CrossRef]

14. Liu, H.; Pan, L.-M.; Hibiki, T.; Zhou, W.; Ren, Q.-Y.; Li, S.-S. One-dimensional interfacial area transport for bubbly two-phase flow in vertical $5 \times 5$ rod bundle. Int. J. Heat Fluid Flow 2018, 72, 257-273. [CrossRef]

15. Smith, T.R.; Schlegel, J.P.; Hibiki, T.; Ishii, M. Two-phase flow structure in large diameter pipes. Int. J. Heat Fluid Flow 2012, 33, 156-167. [CrossRef]

16. Shen, X.; Schlegel, J.P.; Hibiki, T.; Nakamura, H. Some characteristics of gas-liquid two-phase flow in vertical large-diameter channels. Nucl. Eng. Des. 2018, 333, 87-98. [CrossRef]

17. Shen, X.; Sun, H.; Deng, B.; Hibiki, T.; Nakamura, H. Experimental study on interfacial area transport of two-phase bubbly flow in a vertical large-diameter square duct. Int. J. Heat Fluid Flow 2017, 67, 168-184. [CrossRef]

18. Shen, X.; Hibiki, T.; Ono, T.; Sato, K.; Mishima, K. One-dimensional interfacial area transport of vertical upward bubbly flow in narrow rectangular channel. Int. J. Heat Fluid Flow 2012, 36, 72-82. [CrossRef]

19. Ju, P.; Yang, X.; Schlegel, J.P.; Liu, Y.; Hibiki, T.; Ishii, M. Average liquid film thickness of annular air-water two-phase flow in $8 \times 8$ rod bundle. Int. J. Heat Fluid Flow 2018, 73, 63-73. [CrossRef]

20. Liu, Y.; Cui, J.; Li, W.Z. A two-phase, two-component model for vertical upward gas-liquid annular flow. Int. J. Heat Fluid Flow 2011, 32, 796-804. [CrossRef]

21. Dang, Z.; Wang, G.; Ju, P.; Yang, X.; Bean, R.; Ishii, M.; Bajorek, S.; Bernard, M. Experimental study of interfacial characteristics of vertical upward air-water two-phase flow in $25.4 \mathrm{~mm}$ ID round pipe. Int. J. Heat Mass Transf. 2017, 108, 1825-1838. [CrossRef]

22. Gao, Y.; Cui, Y.; Xu, B.; Sun, B.; Zhao, X.; Li, H.; Chen, L. Two phase flow heat transfer analysis at different flow patterns in the wellbore. Appl. Therm. Eng. 2017, 117, 544-552. [CrossRef]

23. Lee, J.; O’Neill, L.E.; Lee, S.; Mudawar, I. Experimental and computational investigation on two-phase flow and heat transfer of highly subcooled flow boiling in vertical upflow. Int. J. Heat Mass Transf. 2019, 136, 1199-1216. [CrossRef]

24. Jiang, C.; Bai, B. Flow patterns and pressure drop of downward two-phase flow in a capsule-type plate heat exchanger. Exp. Therm. Fluid Sci. 2019, 103, 347-354. [CrossRef]

25. Julia, J.E.; Ozar, B.; Jeong, J.J.; Hibiki, T.; Ishii, M. Flow regime development analysis in adiabatic upward two-phase flow in a vertical annulus. Int. J. Heat Fluid Flow 2011, 32, 164-175. [CrossRef]

26. Julia, J.E.; Hibiki, T. Flow regime transition criteria for two-phase flow in a vertical annulus. Int. J. Heat Fluid Flow 2011, 32, 993-1004. [CrossRef]

27. Qiao, S.; Mena, D.; Kim, S. Inlet effects on vertical-downward air-water two-phase flow. Nucl. Eng. Des. 2017, 312, 375-388. [CrossRef]

28. Xue, Y.; Li, H.; Hao, C.; Yao, C. Investigation on the void fraction of gas-liquid two-phase flows in vertically-downward pipes. Int. Commun. Heat Mass Transf. 2016, 77, 1-8. [CrossRef]

29. Dall'Acqua, D.; Terenzi, A.; Leporini, M.; D'Alessandro, V.; Giacchetta, G.; Marchetti, B. A new tool for modelling the decompression behaviour of $\mathrm{CO}_{2}$ with impurities using the Peng-Robinson equation of state. Appl. Energy 2017, 206, 1432-1445. [CrossRef]

30. Afshari, F.; Zavaragh, H.G.; Sahin, B.; Grifoni, R.C.; Corvaro, F.; Marchetti, B.; Polonara, F. On numerical methods; optimization of CFD solution to evaluate fluid flow around a sample object at low Re numbers. Math. Comput. Simul. 2018, 152, 51-68. [CrossRef] 
31. Leporini, M.; Arianna, B.; Marco, F.; Pietro, P. The extension of the 1D two-fluid slug capturing method to simulate slug flow in vertical pipes. Int. J. Numer. Methods Fluids 2020, 1-18. [CrossRef]

32. Al-Kizwini, M.; Wylie, S.; Al-Khafaji, D.; Al-Shamma, A. The monitoring of the two phase flow-annular flow type regime using microwave sensor technique. Meas. J. Int. Meas. Confed. 2013, 46, 45-51. [CrossRef]

33. An, Z.; Ningde, J.; Lusheng, Z.; Zhongke, G. Liquid holdup measurement in horizontal oil-water two-phase flow by using concave capacitance sensor. Meas. J. Int. Meas. Confed. 2014, 49, 153-163. [CrossRef]

34. Da Silva, M.; Thiele, S.; Abdulkareem, L.; Azzopardi, B.; Hampel, U. High-resolution gas-oil two-phase flow visualization with a capacitance wire-mesh sensor. Flow Meas. Instrum. 2010, 21, 191-197. [CrossRef]

35. Damsohn, M.; Prasser, H.-M. High-speed liquid film sensor for two-phase flows with high spatial resolution based on electrical conductance. Flow Meas. Instrum. 2009, 20, 1-14. [CrossRef]

36. Hanafizadeh, P.; Ghanbarzadeh, S.; Saidi, M.H. Visual technique for detection of gas-liquid two-phase flow regime in the airlift pump. J. Pet. Sci. Eng. 2011, 75, 327-335. [CrossRef]

37. Marchetti, J.; Svendsen, H. Improvements on a laser scattering technique for droplet size measurements applied to a gas-liquid separation equipment. Meas. J. Int. Meas. Confed. 2011, 44, 493-499. [CrossRef]

38. Tibiriçá, C.B.; Nascimento, F.J.D.; Ribatski, G. Film thickness measurement techniques applied to micro-scale two-phase flow systems. Exp. Therm. Fluid Sci. 2010, 34, 463-473. [CrossRef]

39. Boden, S.; Bieberle, M.; Hampel, U. Quantitative measurement of gas hold-up distribution in a stirred chemical reactor using X-ray cone-beam computed tomography. Chem. Eng. J. 2008, 139, 351-362. [CrossRef]

40. Heindel, T.J.; Gray, J.N.; Jensen, T.C. An X-ray system for visualizing fluid flows. Flow Meas. Instrum. 2008, 19, 67-78. [CrossRef]

41. Osta, A.R.; Lee, J.; Sallam, K.A.; Fezzaa, K. Study of the effects of the injector length/diameter ratio on the surface properties of turbulent liquid jets in still air using X-ray imaging. Int. J. Multiph. Flow 2012, 38, 87-98. [CrossRef]

42. Roshani, G.H.; Feghhi, S.; Mahmoudi-Aznaveh, A.; Nazemi, E.; Adineh-Vand, A. Precise volume fraction prediction in oil-water-gas multiphase flows by means of gamma-ray attenuation and artificial neural networks using one detector. Meas. J. Int. Meas. Confed. 2014, 51, 34-41. [CrossRef]

43. Roshani, G.H.; Nazemi, E.; Feghhi, S.; Setayeshi, S. Flow regime identification and void fraction prediction in two-phase flows based on gamma ray attenuation. Meas. J. Int. Meas. Confed. 2015, 62, 25-32. [CrossRef]

44. Roshani, G.H.; Roshani, S.; Nazemi, E.; Roshani, S. Online measuring density of oil products in annular regime of gas-liquid two phase flows. Meas. J. Int. Meas. Confed. 2018, 129, 296-301. [CrossRef]

45. Charalampous, G.; Hadjiyiannis, C.; Hardalupas, Y. Comparative measurement of the breakup length of liquid jets in airblast atomisers using optical connectivity, electrical connectivity and shadowgraphy. Meas. J. Int. Meas. Confed. 2016, 89, 288-299. [CrossRef]

46. Japper-Jaafar, A.; Escudier, M.P.; Poole, R.J. Laminar, transitional and turbulent annular flow of drag-reducing polymer solutions. J. Non-Newtonian Fluid Mech. 2010, 165, 1357-1372. [CrossRef]

47. Ismail, I.; Gamio, J.C.; Bukhari, S.; Yang, W.Q. Tomography for multi-phase flow measurement in the oil industry. Flow Meas. Instrum. 2005, 16, 145-155. [CrossRef]

48. Li, Y.; Soleimani, M. Imaging conductive materials with high frequency electrical capacitance tomography. Meas. J. Int. Meas. Confed. 2013, 46, 3355-3361. [CrossRef]

49. Tschentscher, R.R.; Schubert, M.; Bieberle, A.; Nijhuis, T.X.A.; Van Der Schaaf, J.J.; Hampel, U.; Schouten, J.J. Tomography measurements of gas holdup in rotating foam reactors with Newtonian, non-Newtonian and foaming liquids. Chem. Eng. Sci. 2011, 66, 3317-3327. [CrossRef]

50. Zhang, L.; Zhai, Y.; Wang, X.; Tian, P. Reconstruction method of electrical capacitance tomography based on wavelet fusion. Meas. J. Int. Meas. Confed. 2018, 126, 223-230. [CrossRef]

51. Akafuah, N.K.; Salazar, A.J.; Saito, K. Infrared thermography-based visualization of droplet transport in liquid sprays. Infrared Phys. Technol. 2010, 53, 218-226. [CrossRef]

52. Albion, K.; Briens, L.; Briens, C.; Berruti, F. Flow regime determination in horizontal pneumatic transport of fine powders using non-intrusive acoustic probes. Powder Technol. 2007, 172, 157-166. [CrossRef]

53. Chiou, Y.-C.; Li, W.-C. Flaw detection of cylindrical surfaces in PU-packing by using machine vision technique. Meas. J. Int. Meas. Confed. 2009, 42, 989-1000. [CrossRef]

54. Fang, L.; Liang, Y.; Lu, Q.; Li, X.; Liu, R.; Wang, X. Flow noise characterization of gas-liquid two-phase flow based on acoustic emission. Meas. J. Int. Meas. Confed. 2013, 46, 3887-3897. [CrossRef] 
55. Furlan, J.; Mundla, V.; Kadambi, J.; Hoyt, N.; Visintainer, R.J.; Addie, G. Development of A-scan ultrasound technique for measuring local particle concentration in slurry flows. Powder Technol. 2012, 215, 174-184. [CrossRef]

56. Wang, M.; Zheng, D.; Xu, Y. A new method for liquid film thickness measurement based on ultrasonic echo resonance technique in gas-liquid flow. Meas. J. Int. Meas. Confed. 2019, 146, 447-457. [CrossRef]

57. Xu, Y.; Yu, P.; Zhu, Z.; Yuan, C.; Zhang, T. Over-reading modeling of the ultrasonic flow meter in wet gas measurement. Meas. J. Int. Meas. Confed. 2017, 98, 17-24. [CrossRef]

58. Hazuku, T.; Takamasa, T.; Matsumoto, Y. Experimental study on axial development of liquid film in vertical upward annular two-phase flow. Int. J. Multiph. Flow 2008, 34, 111-127. [CrossRef]

59. Hu, H.L.; Dong, J.; Zhang, J.; Cheng, Y.J.; Xu, T.M. Identification of gas/solid two-phase flow regimes using electrostatic sensors and neural-network techniques. Flow Meas. Instrum. 2011, 22, 482-487. [CrossRef]

60. Liu, W.X.; Jin, N.D.; Han, Y.F.; Zhai, L.S.; Chen, X.; Zhang, H.X. Effects of flow patterns and salinity on water holdup measurement of oil-water two-phase flow using a conductance method. Meas. J. Int. Meas. Confed. 2016. [CrossRef]

61. De Jong, J.; Salazar, J.P.L.C.; Woodward, S.H.; Collins, L.R.; Meng, H. Measurement of inertial particle clustering and relative velocity statistics in isotropic turbulence using holographic imaging. Int. J. Multiph. Flow 2010. [CrossRef]

62. Oshinowo, T.; Charles, M.E. Vertical two-phase flow part I. Flow pattern correlations. Can. J. Chem. Eng. 1974. [CrossRef]

63. Troniewski, L.; Ulbrich, R. The analysis of flow regime maps of two -phase gas-liquid flow in pipes. Chem. Eng. Sci. 1984, 39, 1213-1224. [CrossRef]

64. Yamazaki, Y.; Yamaguchi, K. Characteristics of Cocurrent Two-Phase Downflow in Tubes. J. Nucl. Sci. Technol. 1979, 16, 245-255. [CrossRef]

65. Crawford, T.; Weinberger, C.; Weisman, J. Two-phase flow patterns and void fractions in downward flow Part I: Steady-state flow patterns. Int. J. Multiph. Flow 1985, 11, 761-782. [CrossRef]

Publisher's Note: MDPI stays neutral with regard to jurisdictional claims in published maps and institutional affiliations.

(C) 2020 by the authors. Licensee MDPI, Basel, Switzerland. This article is an open access article distributed under the terms and conditions of the Creative Commons Attribution (CC BY) license (http://creativecommons.org/licenses/by/4.0/). 